This item was submitted to Loughborough's Research Repository by the author.

Items in Figshare are protected by copyright, with all rights reserved, unless otherwise indicated.

\title{
Identifying tax implicit equivalence scales
}

PLEASE CITE THE PUBLISHED VERSION

https://doi.org/10.1007/s10888-017-9354-x

\section{PUBLISHER}

(C) Springer

\section{VERSION}

AM (Accepted Manuscript)

\section{PUBLISHER STATEMENT}

This work is made available according to the conditions of the Creative Commons Attribution-NonCommercialNoDerivatives 4.0 International (CC BY-NC-ND 4.0) licence. Full details of this licence are available at: https://creativecommons.org/licenses/by-nc-nd/4.0/

\section{LICENCE}

CC BY-NC-ND 4.0

\section{REPOSITORY RECORD}

van de Ven, Justin, Nicolas Herault, and Francisco Azpitarte. 2019. "Identifying Tax Implicit Equivalence Scales". figshare. https://hdl.handle.net/2134/34108. 


\title{
Identifying tax implicit equivalence scales
}

\author{
Justin van de Ven, Nicolas Hérault and Francisco Azpitarte*
}

\begin{abstract}
This paper describes a simple and tractable method for identifying equivalence scales that reflect the value judgements implicit in a tax and transfer system. The approach depends on two identifying assumptions and a functional description for transfer payments that can be estimated using common publicly available data sources. We use this approach to evaluate tax implicit equivalence scales for the tax-transfer systems of 12 European countries that applied in 2012. Cross-country averages for the tax implicit scales generate a surprising set of stylised results: at low incomes, each additional household member increases the tax implicit scale by approximately 0.5, relative to 1.0 for the first adult; at high incomes, the average tax implicit scales describe variation that is remarkably similar to the modified OECD scale. However, substantial cross-country variation underlies these average scales, suggesting important differences in value judgements underlying the respective tax-transfer systems; differences that can otherwise be difficult to discern in complex and opaque systems.
\end{abstract}

Key Words: equivalence scale, taxation, horizontal equity

JEL Classifications: D31, H23, I38

\section{Introduction}

Equivalence scales are a commonly used metric to summarise differences in the relative needs of heterogeneous households. Despite their widespread use, however, there is no consensus about how such scales should be identified. This paper contributes to the existing literature by proposing a simple analytical approach for deriving equivalence

${ }^{*}$ MIAESR, The University of Melbourne, Vic 3010, Australia. van de Ven is jointly affiliated with the National Institute of Economic and Social Research, SW1P 3HE, London, UK. Azpitarte is jointly affiliated with the Brotherhood of St Laurence, and acknowledges financial support from the Spanish Ministerio de Ciencia e Innovación (grants ECO2008-03484-C0201/ECON and ECO2010-21668-C03-03) and the Xunta de Galicia (10SEC300023PR). We thank four anonymous reviewers and the journal editor for useful comments on earlier drafts. van de Ven also wishes to thank John Muellbauer for extensive preliminary discussions concerning tax implicit scales. This research was supported by the Australian Research Council Centre of Excellence for Children and Families over the Life Course (project number CE140100027). The Centre is administered by the Institute for Social Science Research at The University of Queensland, with nodes at The University of Western Australia, The University of Melbourne and The University of Sydney. The views expressed herein are those of the authors and are not necessarily those of the Australian Research Council. Corresponding author: justin.van@unimelb.edu.au. 
scales that reflect the value judgements implicit in tax and transfer policy; hereafter referred to as tax implicit (equivalence) scales. The proposed tax implicit scales depend upon qualitatively different assumptions to other scales that are in common use, and can be identified using widely available data sources. The proposed scales consequently provide both a transparent measure of the relative treatment by a tax-transfer system of alternative tax units, and a potentially useful alternative statistic to control for tax unit heterogeneity when conducting distributional analyses.

Most empirically evaluated equivalence scales are based on consumer demand theory. ${ }^{1}$ Three key conceptual problems can be identified with demand based scales (e.g Chiappori [3], Section 1): the focus on family rather than individual specific utilities; the assumption that family preferences are fully defined by a family's characteristics; and the assumption of a strong version of interpersonal comparison of utilities that applies both within and between families. ${ }^{2}$ Such criticisms have long been recognised, resulting in claims that "the equivalence scales required for welfare comparisons are logically distinct from those which arise in demand analaysis", Pollak and Wales ([5], p. 216); Muellbauer [6].

The resulting confusion concerning how equivalence scales are most appropriately identified has motivated a popular trend toward the use of scales that take highly stylised forms. The modified OECD scale, first proposed by Hagenaars et al. [7], is one such measure. ${ }^{3}$ Although stylised scales tend to be highly transparent, they also provide a restrictive description of the relative needs of heterogeneous tax units, which suggests a need for associated sensitivity analysis. This points to the usefulness of an identification approach for equivalence scales that differs substantively from those applied in the established literature.

A number of alternative approaches for identifying equivalence scales have been suggested in the recent literature. Recognising that observable decisions can at best be used to obtain an ordinal description of preferences, Browning et al. [9] suggest an empirical approach designed to identify 'indifference scales' that describe the income differences an individual would require to attain the same indifference curve within alternative family

\footnotetext{
${ }^{1}$ Deaton and Muellbauer [1], chapters 7 to 9 , provides a detailed discussion of the theoretical underpinnings of the demand based approach for estimating equivalence scales. For a discussion of the advantages and disadvantages of alternative equivalence scales, see also Coulter et al. [2].

${ }^{2}$ See also the influential critique of demand based equivalence scales by Blundell and Lewbel [4].

${ }^{3}$ The modified OECD scale is based upon "expert opinion"; see Orshansky [8] for a comparable scale also based on expert opinion.
} 
contexts. A more radical departure from consumer based equivalence scales is to elicit the information necessary for identification directly from survey respondents. The intuitive appeal of 'subjective equivalence scales' evaluated using this method is somewhat tempered by the counterfactual nature inherent in associated survey questions, and a general lack of statistical consistency identified in the related literature. ${ }^{4}$ This paper focuses on the use of tax policy as an alternative source for identifying equivalence scales.

Tax implicit equivalence scales are rarely considered in the existing literature. Yet, tax and transfer systems translate an explicit defined set of tax unit characteristics (defined broadly to include income and wealth) into disposable income. The positive relationship that exists between disposable income and welfare implies that transfer systems reflect a set of value judgements concerning the relative merits of alternative tax units; value judgements that provide a potential basis for identifying an equivalence scale.

A small number of studies have evaluated the equivalence scales implicit in selected transfer schemes, usually focussing upon minimum income payments. Olken [11] suggests a method for identifying 'community equivalence scales', on the assumption that the individuals who receive social assistance are selected to maximise an assumed social welfare function. Given explicit assumptions concerning the social welfare function, it is possible to derive a closed-form solution for the proportion of the population in receipt of support. This closed-form can be estimated as a standard binary choice model to identify the parameters of a policy implicit equivalence scale. Olken uses this approach to estimate the equivalence scales implied by a subsidised rice program offered to poor households in Indonesia. ${ }^{5}$

Other studies have evaluated the scales implicit in selected transfer schemes by taking the ratio of the payments made to alternative household types; e.g. HMSO [13] for an early example in relation to UK income support payments, and Stewart [14] for old age pensions. This latter approach has the advantage that it does not depend upon assumptions concerning the existence of a social welfare function or the specification of the equivalence scale. It is also tacitly supported by the observation that some countries (e.g. Germany, the Netherlands, Sweden, Norway) have set income support payments

\footnotetext{
${ }^{4}$ Bishop et al. [10] attempt to mitigate the criticisms associated with use of subjective equivalence scales by drawing on a relatively large survey sample, and by focussing on measures of poverty rather than inequality more generally.

${ }^{5}$ See also Lall et al. [12] for equivalence scales implicit in a housing subsidy in South Africa.
} 
with reference to budget standards for low income households. ${ }^{6}$

This study contributes to the above literature by describing a simple analytical approach for identifying equivalence scales implicit in an entire tax and transfer system, based on two identifying assumptions and a functional description for transfer payments. The two assumptions upon which our identification approach is based - horizontal equity and tax independence - bear close similarities to assumptions commonly adopted in empirical studies of inequality and tax progressivity. Furthermore, the functional description of the transfer system required for the identification approach is present in a range of tax-transfer calculators in current use (e.g. Euromod, TAXSIM, TAXBEN, MITTS, SWITCH, etc), or can be estimated from common micro-data sources (e.g. EU-SILC, the US Current Population Survey, the UK Family Resources Survey, the Australian Survey of Income and Housing Costs).

We apply the approach to obtain tax implicit equivalence scales for 12 European countries. This application sheds light on the great diversity of relativities implicit in transfer policies in Europe. It also highlights how these tax implicit relativities vary with income, in contrast to the common assumption of base independence assumed for equivalence scales in the existing consumer demand literature.

The analytical approach is described in Section 2, and results for 12 European countries are presented in Section 3. Discussion and directions for further research are provided in a concluding section.

\section{A simple method for identifying tax implicit equiv- alence scales}

We are concerned with identifying the value judgements implicit in the relative treatment of alternative tax units by an entire tax and transfer system, and not any single transfer scheme taken in isolation. Assume that there exists a decision body that designs and implements $T \in \mathbb{R}$, which assigns a unique net-transfer payment, $t_{i}$, to each individual $i$ from a set of tax units $I . t>0$ indicates a net tax levied, and $t<0$ a net transfer received. Assume that the design of $T$ depends upon the rank-ordering of all tax units $i \in I$ in terms of relative merit, as perceived by the decision body. Before proceeding with the exposition, it is useful to address directly the intended interpretation of $T$.

\footnotetext{
${ }^{6}$ Budget standards, also referred to as minimum income standards or reference budgets, are priced baskets of goods and services; e.g. [15], [16].
} 
It is not suggested that $T$ be interpreted as representing a 'social consensus'; the heated debate that often accompanies transfer policy reforms suggests that no consensus view may exist (Coulter et al. [2], p. 100). Rather, $T$ is interpreted as the product of a policy compromise, in which possibly diverse social views concerning relative merit interact with the prevailing policy and administrative environment. Furthermore, we allow the 'merit' of a tax unit to depart from individual specific welfare to accommodate non-welfarist objectives that might influence the design of tax-transfer policy, such as the determinants of electoral success or the goals of an established bureaucracy (e.g. Atkinson and Stiglitz [17], p. 9). Hence, the relative merit for tax purposes implicit in $T$ should be understood as a product of the underlying policy compromise, as opposed to some form of unadulterated social preference ranking. We return to discuss the practical implications of this policy compromise for tax implicit scales in Section 3.2.

Assume that the merit of any tax unit $i$ depends only on that unit's characteristics vector $\left(x_{i}, \phi_{i}, t_{i} ; x_{i} \in X, \phi_{i} \in \Phi, t_{i}=T\left(x_{i}, \phi_{i}\right)\right)$, and is independent of the characteristics of all other units in population $I . X$ is the vector of private pre-tax and transfer incomes (hereafter pre-tax income), and $\Phi$ the set of all other relevant characteristics including, for example, labour status, marital status, number and ages of children, health status and so on. The net transfer payment $t_{i}$ is included in each tax unit's characteristics vector, which is central to the identification strategy set out below.

Denote by $\succeq_{D}$ the rule governing the merit ordering of alternative tax unit vectors $(x, \phi, t)$. Thus, $\left(x_{i}, \phi_{i}, t_{i}\right) \succeq_{D}\left(x_{j}, \phi_{j}, t_{j}\right)$ implies that tax unit $i$ is at least as meritorious as tax unit $j$ for the purposes of taxation. Similarly, $\left(x_{i}, \phi_{i}, t_{i}\right) \sim_{D}\left(x_{j}, \phi_{j}, t_{j}\right)$ implies that tax units $i$ and $j$ have the same merit for tax purposes. It is assumed that the rule $\succeq_{D}$ can be represented by the real-valued function $W(x, \phi, t) \in \mathbb{R}$, such that $W\left(x_{i}, \phi_{i}, t_{i}\right) \geq$ $W\left(x_{j}, \phi_{j}, t_{j}\right)$ if and only if $\left(x_{i}, \phi_{i}, t_{i}\right) \succeq_{D}\left(x_{j}, \phi_{j}, t_{j}\right)$ for all $(i, j \in I)$.

We seek a convenient description of the bearing that characteristics $(x, \phi, t)$ have on tax unit merit, relative to a reference unit. Without loss of generality, define:

$$
W(x, \phi, t)=\frac{x-t}{w(x, \phi, t)}
$$

From equation (1), the bearing that alternative characteristics have on tax unit merit can be defined in the familiar form of a (relative) equivalence scale. Suppose that all reference units possess the characteristic vector $\phi_{r}$, and consider the impact that any given characteristic vector, $\phi_{i}$, has on tax unit merit. If tax unit $i$ with characteristics 
$\left(x_{i}, \phi_{i}, t_{i}\right)$ has the same merit as reference unit $r$ with characteristics $\left(x_{r}, \phi_{r}, t_{r}\right)$, then:

$$
W\left(x_{i}, \phi_{i}, t_{i}\right)=W\left(x_{r}, \phi_{r}, t_{r}\right) \Rightarrow a\left(x_{i}, \phi_{i}, t_{i}\right)=\frac{w\left(x_{i}, \phi_{i}, t_{i}\right)}{w\left(x_{r}, \phi_{r}, t_{r}\right)}=\frac{x_{i}-t_{i}}{x_{r}-t_{r}}
$$

In equation (2), $a\left(x_{i}, \phi_{i}, t_{i}\right)$ is our focus of interest, which we refer to as a tax implicit equivalence scale. Discounting the after-tax income of tax unit $i$ by the relevant tax implicit scale $a\left(x_{i}, \phi_{i}, t_{i}\right)$ gives the after-tax income that the reference unit with characteristics $\phi_{r},\left(x_{r}-t_{r}\right)$, would require to be of equal merit to tax unit $i$.

For any given vector $\left(x_{i}, \phi_{i}, t_{i}\right) \neq\left(x_{r}, \phi_{r}, t_{r}\right)$, both $a\left(x_{i}, \phi_{i}, t_{i}\right)$ and $\left(x_{r}-t_{r}\right)$ are unobserved, and therefore cannot be inferred from equation (2) alone. To resolve this indeterminacy, assume that $T$ satisfies the principle of horizontal equity (HE): ${ }^{7}$

Condition HE: Any two tax units of equal tax merit in the presence of a tax must also have equal merit if, ceteris paribus, all taxes were set to zero

The condition HE requires:

$$
W\left(x_{i}, \phi_{i}, t_{i}\right)=W\left(x_{r}, \phi_{r}, t_{r}\right) \Leftrightarrow W\left(x_{i}, \phi_{i}, 0\right)=W\left(x_{r}, \phi_{r}, 0\right)
$$

Substituting equation (1) into (3) and rearranging:

$$
a\left(x_{i}, \phi_{i}, t_{i}\right)=\frac{w\left(x_{i}, \phi_{i}, t_{i}\right)}{w\left(x_{r}, \phi_{r}, t_{r}\right)}=\frac{x_{i}-t_{i}}{x_{r}-t_{r}} \Leftrightarrow a\left(x_{i}, \phi_{i}, 0\right)=\frac{w\left(x_{i}, \phi_{i}, 0\right)}{w\left(x_{r}, \phi_{r}, 0\right)}=\frac{x_{i}}{x_{r}}
$$

Note that HE has not resolved the indeterminacy of our problem, as it has added one equation and one unknown, $a\left(x_{i}, \phi_{i}, 0\right)$. An additional restriction is therefore required for identification. We propose the condition of tax independence (TI) to resolve the remaining indeterminacy:

Condition TI: Relative merit for tax purposes is independent of the tax function

TI requires that the same tax implicit scale applies to both pre-tax and after-tax incomes; i.e. $a(x, \phi, 0)=a(x, \phi, t)=a(x, \phi)$ for all $(x \in X, \phi \in \Phi)$. A necessary and sufficient condition for TI is that $w(x, \phi, t)=w^{\prime}(x, \phi)$ for all $(x \in X, \phi \in \Phi, t \in T)$. Note that this restriction does not also imply that $W($.$) is independent of t$; rather, it requires that there exists a monotonic transformation of $W($.$) that is linear in t$. Note also that HE and TI do not require $a($.$) to be independent of pre-tax income x$, which is likely to be important in most practical contexts. Imposing TI, and rearranging (4) gives:

$$
\frac{t_{r}}{x_{r}}=\frac{t_{i}}{x_{i}}
$$

\footnotetext{
${ }^{7}$ This interpretation of $\mathrm{HE}$ can be contrasted with stronger interpretations that impose no-reranking conditions as considered, for example, by Plotnick [18].
} 
Hence, whereas Engel's original proposition for identifying an equivalence scale was that any two tax units should be considered 'equally well-off' if they devote an equal share of their income to food expenditure, the current framework suggests that they should be considered of 'equal merit for tax purposes' if they pay an equal share of their income in (net) taxes.

Modern tax and transfer systems share two key features. First, they tend to provide financial subsidies at low or negative pre-tax incomes. Secondly, most systems include a degree of progressivity, characterised by increasing marginal tax rates. The identification approach that we suggest for tax implicit scales is based upon these two features, in combination with equation (5).

Define the set of non-income characteristics for analysis, $\hat{\Phi}$. For each feasible combination of non-income characteristics, $\phi_{i} \in \hat{\Phi}$, evaluate the average tax rate as a function of pre-tax income; $f_{i}(x)=T\left(x, \phi_{i}\right) / x$. The two features of modern tax-transfer systems referred to above imply that average effective tax rates of modern progressive tax-transfer systems tend to increase in pre-tax income, rising from negative infinity about zero pretax income, and asymptoting toward the higher marginal tax rate at very high pre-tax incomes. Select a reference unit $\phi_{r}$, so that $T\left(0, \phi_{r}\right) \neq 0$ and the function $f_{r}$ varies strictly monotonically over each of the domains $x>0$ and $x<0$; note that the domain $x<0$ is ignored in much of the inequality literature, but is included here for completeness. For the strictly positive domain of pre-tax income, the tax implicit equivalence scale of any tax unit, $i$, with characteristics $\left(x_{i}, \phi_{i}\right)$ measured relative to the reference unit $\phi_{r}$ is then equal to the ratio $x_{i} / \hat{x}_{r}$ (from equation 4 ), where $\hat{x}_{r}$ is the unique value given by the condition $f_{r}\left(\hat{x}_{r}\right)=f_{i}\left(x_{i}\right)$ (from equation 5 ), obtained either by inverting $f_{r}($.$) or via a search routine over the strictly positive domain. A similar approach can be$ used to evaluate tax implicit scales over the domain of strictly negative pre-tax incomes. At zero pre-tax income, all tax units for which $T\left(x, \phi_{i}\right)<0$ will have the same average effective tax rate (negative infinity), and the tax implicit equivalence scale of any unit can then be evaluated as $T\left(0, \phi_{i}\right) / T\left(0, \phi_{r}\right)$ (from equation 2$)$.

Although strict monotonicity of the average tax rates in pre-tax income is a property that tends to be supported by modern progressive tax and transfer systems, it is not guaranteed in practice. Poverty traps remain prevalent, sometimes hidden by system complexity and overlapping withdrawal of alternative benefits payments. Furthermore, at very high incomes marginal effective tax rates can fall very substantively as the affluent take advantage of complex tax minimisation strategies that are out of the reach 
of the majority of tax payers. ${ }^{8}$ Of the EU15 countries described by Euromod for 2012, for example, average tax rates of single working aged adults (a convenient reference unit) are strictly increasing in 10 countries only. Average tax rates are non-decreasing but flat over an appreciable income range in Portugal and over a small income band in Finland. Average tax rates are decreasing over a substantial income range in Spain and are incomplete in two countries (Greece and Italy). Where the average tax rates of the reference tax unit are found to be non-increasing in pre-tax income, we suggest that any indeterminacy of the tax implicit scale can be resolved by selecting equals to obtain the smallest mis-match between pre-tax incomes that is consistent with condition (5). We return to discuss scales based on Euromod in Section 3.

The structure that we impose on preference orderings to identify equivalence scales is not novel. Consider, for example, the established literature that identifies equivalence scales based on consumer demand theory. As observed data do not generally provide information on the joint distribution of preferences over goods and household demographics that are required for welfare comparisons ([5]; [4]), an influential method for identifying equivalence scales based on consumer demand theory is to assume a utility structure that satisfies the condition of Independence of Base (IB; [19] and [20]). ${ }^{9}$ IB requires that utility equality is preserved under income scaling. This is similar in spirit to the constraints imposed by HE and TI, which require that tax merit equality is preserved by scaling of average tax rates. Whereas IB implies that the equivalence scale will be independent of utility and income, HE and TI imply that tax implicit equivalence scales will be independent of the tax function, $T$.

A feature of the literature that explores expenditure-based equivalence scales is that identifying assumptions like IB tend to impose limitations on preferences that vary across household types, or the way that demographic variables enter demand equations, which facilitate econometric evaluation and testing. In contrast, the system that we suggest above for identifying tax implicit scales is exactly identified, so that the joint

\footnotetext{
${ }^{8}$ In the 14 August 2011 edition of the New York Times, for example, the financier Warren Buffet claimed that his effective average tax rate was 17.4 per cent on annal taxable earnings of just under $\$ 7$ million. In contrast, he reported that the average tax rates of the other 20 staff in his office who presumably earned considerably less than he did - ranged from 33 to 41 percent, and averaged 36 percent.

${ }^{9}$ Blackorby and Donaldson [20] call this property equivalence scale exactness, and show that it permits identification if preferences are not piglog. Donaldson and Pendakur [21] propose a generalisation of the IB property that imposes less restrictive conditions on preferences allowing equivalence scales to vary with utility levels.
} 
assumptions of HE and TI cannot be tested.

Testable implications require over-identifying assumptions, and there are very few generally accepted principals of taxation that we might refer to when formulating such assumptions. The condition of HE is a notable exception, but as our above analysis shows, this condition is insufficient to permit identification of a tax implicit equivalence scale on its own. Any attempt to define a testable criterion for identifying tax implicit equivalence scales must therefore take account of alternative considerations.

One justifiable approach is to select identifying assumptions that are in some sense analytically convenient. This is one motivation for relying on the condition TI, which ensures that the same tax implicit scale is applicable for both pre-tax and post-tax incomes. Our above analysis indicates that a stronger set of assumptions would be required to ensure that tax implicit equivalence scales are independent of income. A further implication of our above analysis is that the assumptions required to ensure income independent tax implicit equivalence scales would also result in testable implications, consistent with consumer demand theory in relation to the IB condition. We have not, however, pursued this line of enquiry for two reasons. First, we agree with the proposition of Seneca and Taussig ([22], p. 255), who suggest that "the most interesting and important issues involving the application of equivalence scales to tax equity questions are intimately bound up with the variation of equivalence scales with the level of income". Secondly, the limited empirical analysis that we have conducted using the above identifying criteria suggest that any over-identifying assumptions required to ensure that tax implicit equivalence scales are independent of income are likely to be strongly rejected by the data, echoing findings in the consumer-demand literature. ${ }^{10}$ We present one such analysis below.

\section{Tax implicit scales for a sample of European coun- tries}

This section illustrates how tax implicit equivalence scales can be used to shed light on the relativities implicit in transfer policy. We begin by describing how the identification method described in Section 2 has been implemented, using a publicly available data

\footnotetext{
${ }^{10}$ Several papers have tested the independence of base assumption using parametric (Blundell and Lewbel [4]; Pashardes [23]) and semiparametric methods (Blundell et al. [24]; Pendakur [25]). Dickens et al. [26] test the IB hypothesis in the context of linear and non-linear demand models. All these papers find statistical evidence to reject the demand restrictions implied by the IB condition.
} 
source. Our objective here is to walk the reader through the steps that we have implemented to arrive at the scales that are reported, and to point out potential pit-falls along the way. Estimates of the implicit equivalence scales for a sample of 12 European countries are then presented and the commonalities and differences in the implicit fiscal relativities across countries discussed.

\subsection{Identifying tax implicit scales}

The identification method described in Section 2 requires a description of the function translating individual specific characteristics into net transfer payments, $T(x, \phi)$. Approximations to country specific functions considered here were derived using Euromod, a tax-transfer microsimulation model for the European Union. Euromod is free of charge for non-commercial use, and the current application requires only the tax-transfer calculator of the model. This simplifies the associated application process, as it is not necessary to obtain access to the extensive micro-data that are the basis for microsimulation projections using Euromod; see [27] for a technical description of the model, and www.euromod.ac.uk for information concerning the application process.

After installing the Euromod software (version 1.10.2 was used here) and extracting the associated 'content files', the 'hypothetical data' application provided with the model was used to generate a synthetic data-set comprised of single adults with up to one dependent child, and adult couples with up to three dependent children. Consistent with the focus of most tax and transfer systems, the current analysis is organised around family units, comprised of a single adult or partner couple, and their dependent children (sometimes referred to as benefit units). All single adults were defined as 32 year old females, not studying, and educated to an upper secondary qualification. Those in work were defined as employees in the services industry, working in clerical occupations for 12 months. Partners, wherever considered for analysis, were defined as 36 year old males, with the same education as their spouses. The first child in each family was defined as a 3 year old female, the second a 5 year old male, and the third a 7 year old female. All individuals were denoted as free from disability, and all non-labour sources of income, rent, mortgage interest, and private pension contributions were set to zero.

The hypothetical data application of Euromod projects a range of employment incomes for each set of family characteristics described above. It does this by assuming a fixed hourly wage rate, and increasing labour supply at hourly intervals from 0 to 
99 hours per week per adult. These data, however, complicate the current analysis, because they introduce confounding effects associated with the division of labour and employment income among family members. In the case of the UK, for example, income of couples is taxed on an individual (not joint) basis, and some transfers only become payable if all adults in the family work at least 15 hours per week. A full description of the function translating individual characteristics into a tax implicit scale requires as arguments all of the characteristics that affect levied taxes and eligible transfers in a country. In the UK context, this would mean including the income of each adult family member, and their respective hours of employment in the description of the tax implicit scale.

The dimensionality of tax implicit scales is limited here by comparing families that differ only in relation to pre-tax income, and the number and age of family members. This was achieved by (manually) amending the hypothetical data generated by Euromod so that one adult family member was defined as working for 35 hours per week wherever employment income was greater than zero. Furthermore, family labour income was adjusted to increase at intervals of 10 Euros between 0 and 1000 Euros per month, and by 50 Euros between 1050 and 10000 Euros per month (implying 281 observations for each family type). This 'training data-set', which is available upon request from the authors, was submitted to Euromod's tax-transfer calculator for 2012, for each country in the EU15, to generate measures of post-tax and transfer incomes. Default options for the tax-transfer calculator were adopted, subject to the assumption of full take-up of eligible transfer payments. Minimum wages were suppressed for the analysis, and all financial data were defined in a common currency (Euros). Each country specific model was also directed to report household level output.

Three EU15 countries were excluded from the analysis. Pre-tax and transfer income for France appeared to be subject to top-coding by the Euromod tax-transfer calculator, motivating exclusion of that country from the analysis. The Euromod tax-transfer calculator generated zero transfer income for Greece and Italy at zero hours of employment. As both countries provide a welfare safety net for the unemployed, these incomplete tax schedules reported by Euromod were omitted from the analysis. Post-tax and transfer income generated by Euromod for all other countries appeared sensible, subject to three minor complications. In the case of Finland, transfer income at zero hours of employment showed important differences with the Euromod report for this country (Ahola et al. [28], p. 20). For this reason Finland was excluded from the analysis at zero pre-tax 
income. In the cases of Denmark and Ireland, post-tax and transfer income generated by Euromod falls sharply between 0 and 10 Euros per month, as transfers are withdrawn due to the assumption of 35 hours of labour per week. These sharp falls in disposable income are of no practical relevance, due to the minimum effective wage rates prevailing in the respective countries, but do complicate evaluation of tax implicit equivalence scales. ${ }^{11}$ For this reason, tax implicit equivalence scales reported at positive but low incomes (below approximately 1500 Euro per month) should be treated with caution for all countries, especially Denmark and Ireland.

The reference unit assumed for analysis is a single adult without dependent children. All calculations, tables and figures were produced by a single Stata 'do' file that is available upon request from the authors. The different assumptions concerning labour supply at zero and positive pre-tax income motivate separate treatment for evaluation of tax implicit scales. Following the methodology set out in Section 2, the Stata program evaluates the tax implicit scale of any family at zero pre-tax income by dividing the family's post-tax and transfer income by the post-tax and transfer income of the reference unit when that unit also has zero pre-tax income. If target pre-tax income is greater than zero, the Stata routine identifies the average effective tax rate associated with the prevailing family type, which we referred to here as the 'target tax rate'. The Stata routine then searches for 'reference measures' of pre-tax income, at which the average effective tax rate for the reference unit is equal to the target tax rate. This search is conducted assuming that average tax rates vary linearly between the 280 discrete points with positive pre-tax income described by Euromod's training data-set for the reference unit. Multiple reference measures of pre-tax income were identified in a few cases for Spain, Finland and Portugal, as the reference average tax rates identified for each of those countries are not strictly monotonic in pre-tax income. In these few cases, the Stata routine is designed to select the reference measure of pre-tax income that is closest to the prevailing target pre-tax income (see previous section). The equivalence scale is then evaluated as the prevailing target pre-tax income divided by the selected reference measure of pre-tax income.

\footnotetext{
${ }^{11}$ The statutory minimum wage in 2012 in Ireland was 1461.85 Euros per month, compared with unemployment benefits for single adults without children worth 815.92 Euros per month. Although there was no statutory minimum wage in Denmark in 2012, enterprise agreements implied an average minimum wage of approximately 95 kroner per hour, equal to 2197.51 Euros per month. This compares with unemployment benefits for single adults without children in Denmark worth 1065.02 Euros per month.
} 
Before moving on to the empirical results, two important qualifications are of note. First, Euromod is under continual development, and consequently the results presented in this paper may not match those that would be obtained using versions of the model other than 1.10.2. Secondly, the scales that are reported here reflect only those tax and transfer schemes that are represented in Euromod. Although a great deal of care is exercised by the Euromod team to capture cash transfers, the model does not extend to include in-kind benefits. Paulus et al. [29] report analysis that augments the cash transfers represented in Euromod to take account of in-kind benefits for housing, education, and health care for a sample of five European countries (Belgium, Germany, Greece, Italy, and the UK). This analysis reveals that, although the in-kind benefits are qualitatively smaller in magnitude than the coincident cash transfers, the in-kind benefits do have an important bearing on distributional measures as they are skewed toward low income households. Furthermore, the study reveals important differences in the scale of in-kind benefits provided in the sample of countries considered. Accounting for such factors would consequently seem an important avenue for further research.

\subsection{Tax implicit scales for EU15 countries}

The equivalence scales that were derived as discussed above provide a fascinating insight into the relativities that are implicit in tax and transfer policy adopted among EU15 countries. Table 1 reports the tax implicit scales evaluated at zero pre-tax income, which differ from the other scales discussed here because they are based on the assumption of zero (rather than 35) hours of employment.

Table 1 indicates that tax implicit equivalence scales at zero pre-tax income strictly increase with family size in all $11 \mathrm{EU}$ countries $^{12}$. This reflects the fact that transfers (as reported by Euromod) tend to rise with the number of family members. Focussing on the country averages reported in the last row of Table 1, the addition of each family member tends to increase eligible transfer payments by approximately half the transfers of a single childless adult. The relative simplicity of this variation, however, belies substantial cross-country variation indicated by the remaining statistics reported in the table.

Countries are approximately evenly split between those that provide greater transfer payments in respect of the first dependent child of single adults, and those that

\footnotetext{
${ }^{12}$ Finland is excluded from Table 1, as discussed in Section 3.1.
} 
Table 1: Tax implicit equivalence scales at zero pre-tax income, by country for 2012

\begin{tabular}{lcccccc}
\hline Country & $\begin{array}{c}\text { single adult } \\
\text { no children }\end{array}$ & $\begin{array}{c}\text { single adult } \\
\text { 1 child }\end{array}$ & $\begin{array}{c}\text { couple } \\
\text { no children }\end{array}$ & $\begin{array}{c}\text { couple } \\
\text { 1 child }\end{array}$ & $\begin{array}{c}\text { couple } \\
\text { 2 children }\end{array}$ & $\begin{array}{c}\text { couple } \\
\text { children }\end{array}$ \\
\hline \hline AT & 1.000 & 1.270 & 1.500 & 1.770 & 2.256 & 2.988 \\
BE & 1.000 & 1.596 & 1.333 & 1.539 & 1.786 & 2.149 \\
DE & 1.000 & 1.757 & 1.719 & 2.244 & 2.778 & 3.417 \\
DK & 1.000 & 1.494 & 2.000 & 2.626 & 2.771 & 2.883 \\
ES & 1.000 & 1.154 & 1.081 & 1.202 & 1.324 & 1.446 \\
IE & 1.000 & 1.330 & 1.664 & 1.994 & 2.324 & 2.664 \\
LU & 1.000 & 1.370 & 1.504 & 1.804 & 2.154 & 2.614 \\
NL & 1.000 & 1.458 & 1.409 & 1.572 & 1.684 & 1.786 \\
PT & 1.000 & 1.723 & 1.700 & 2.386 & 3.071 & 3.772 \\
SE & 1.000 & 1.653 & 1.782 & 2.461 & 3.153 & 3.957 \\
UK & 1.000 & 2.161 & 1.570 & 2.730 & 3.647 & 4.563 \\
\hline Average & 1.000 & 1.542 & 1.569 & 2.030 & 2.450 & 2.931 \\
\hline \hline
\end{tabular}

Source: Authors' calculations using data from Euromod v 1.10 .2

Notes: 'Average' reports unweighted arithmetic mean of country specific scales

provide greater transfers for a spouse. In Austria (AT), Denmark (DK), Ireland (IE), Luxembourg (LU), and Sweden (SE), transfers payable for a spouse in a childless family exceed those payable for the first dependent child of a single parent by between 20 and $100 \%$. This reflects the greater living expenses that are generally associated with adults than children in the existing equivalence scales literature. Results obtained for Belgium (BE), Spain (ES) and the UK stand at the opposite end of the scale, where the transfer payments associated with a spouse are a fraction of the transfers associated with the first dependent child of a single parent. Furthermore, results obtained for the three remaining EU15 countries reported in the table (Germany (DE), Netherlands (NL), and Portugal (PT)) all indicate slightly higher transfers payable for the first dependent child of a single-parent, than for a spouse in a childless household.

In all cases other than LU, those tax-transfer systems for which the tax implicit equivalence scale of single adults with one dependent child are greater than those of adult couples without children also show larger increases in scale for the first dependent child among single adults than couples. This result suggests that some systems are especially adapted to support single parents, relative to other demographic groups. Considering the incremental increase in scale associated with the addition of dependent children in couple households reveals that most countries tend to provide increasingly generous benefits to larger families. This is most clearly evident for Austria, Belgium, and Luxembourg, where the incremental increase in benefits in respect of the third child is over half as great 
again as those payable for the first dependent child. The reverse is true in Denmark, the Netherlands and the UK, where the incremental benefits for the third dependent child are at least 20 percent less than those for the first child.

These results demonstrate how far the tax-transfer systems of many EU15 countries fail to reflect expenditure needs as described by the consumer demand literature. As noted previously in this paper, departures between tax implicit and consumption based equivalence scales may be interpreted as indicating the extent to which formulation of transfer policy depends on a wider set of considerations than a limited response to consumption needs. What is perhaps surprising, however, is the diversity of approaches adopted, even among a sample of countries that share many cultural similarities; as in the case of Austria, relative to Germany and the Netherlands, relative to Belgium.

It is beyond the scope of the current study to conduct a detailed analysis of the cross-country differences of tax implicit scales that are identified above. Nevertheless, it is useful to discuss issues concerning the practical importance of differences reported in the table. One issue that cannot be inferred directly from any tax implicit scale concerns the relative concentration of the respective population in relation to the tax implicit scales; the scales reported in Table 1, for example, apply only to individuals with zero pre-tax incomes, and will consequently be more important in some countries (where unemployment rates are relatively high) than others. Another important factor determining the practical importance of alternative tax implicit scales concerns their persistence through time. Although there is typically a great deal of persistence in the underlying features of modern tax and transfer systems, the details of individual transfer schemes also tend to be in a constant state of flux as they are adapted to the changing political and institutional context. While the country specific tax implicit scales discussed above describe relative tax merit (as defined in Section 2) applicable in 2012, they do not indicate the extent to which these relativities persist through time.

One plausible approach for distinguishing persistent features of tax implicit scales applicable in any country would be to consider moving averages of scales evaluated on the transfer policy applicable in the country through time. In a similar vein, the crosscountry averages reported in the last row of Table 1 aggregate over diverse political and institutional contexts, and may consequently provide a more reliable indication of persistent features of transfer policy than any of the country specific scales taken in isolation. Our analysis above indicates substantive cross-country variation between tax implicit scales; exploring the extent of intertemporal variation of country specific scales 
Figure 1: Tax implicit equivalence scales by family type and pre-tax income, EU15 country averages for 2012

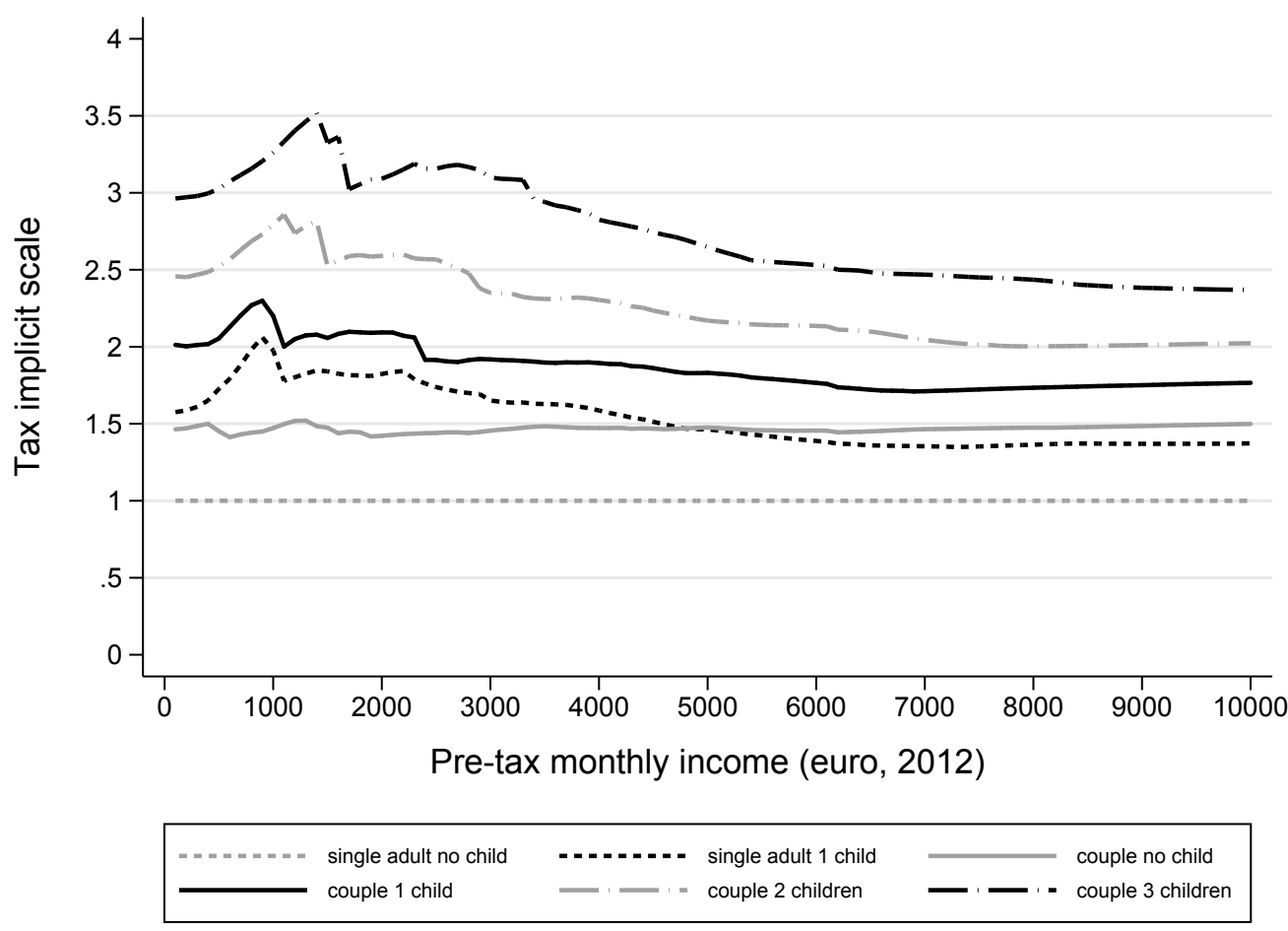

Source: Authors' calculations using data derived from Euromod v 1.10.2

Notes: Statistics report arithmetic averages over country specific scales calculated for AT, BE, DE, DK, ES, FI, IE, LU, NL, PT, SE and UK

remains an interesting dimension for further research.

As alluded to at the end of Section 2, many of the tax implicit equivalence scales considered for EU15 countries vary substantially with pre-tax income. Figure 1 reports variation of tax implicit scales with pre-tax income, averaged over the twelve EU15 countries for which data were obtained from Euromod (i.e. the 11 countries reported in Table 1 plus Finland). This figure indicates that the tax implicit equivalence scales of families with children tend to rise with pre-tax income, to peak somewhere between 1000 and 1500 Euros per month, before falling away and levelling off at higher incomes. For comparison, minimum full-time incomes in the EU15 (where they existed) were worth approximately 1200 Euros per month in 2012, and average incomes were approximately 3150 Euros per month. At the top of the considered range of pre-tax income, tax implicit scales of families with children are compressed by 10 to $20 \%$, relative to their respective values at the bottom of the income range. In contrast, the tax implicit scales of childless couples are fairly constant over the entire income range. Interestingly, the values of the 
tax implicit scales at the top of the considered pre-tax income range broadly correspond with the modified OECD scale, which assigns a value of 1.0 to the family reference person, 0.5 to each additional family member over age 13 , and 0.3 to each child aged 13 and under.

While the scales reported in Figure 1 do appear to us rationalisable, it is beyond the scope of the current study to second-guess the motives that underly them. Nevertheless, it is useful to discuss here the mechanics that are responsible for the reported variation of tax implicit scales with pre-tax income. The key factor responsible for the initial climb in scales associated with families with children is the withdrawal of means-tested transfer payments, which tend to occur at lower incomes among families without children than those with children. In this case, the rises reported for tax implicit scales of families with children are consequently not an indication of increased eligibility for transfer payments among these families, but of transfers withdrawal from single childless adults. That a similar rise in tax implicit scales is not observed for couples without children indicates that these families are subject to similar terms concerning benefits withdrawal as single adults without children at low incomes (generating similar variation of average effective tax rates with pre-tax income).

As in relation to the tax implicit scales at zero pre-tax income discussed above, a great deal of cross-country variation underlies the average scales that are reported in Figure 1. We single out examples of two broad 'schools' for discussion here, and report graphs and associated discussion for all countries as part of the "Online Supplemental Material" to this paper.

The top panel of Figure 2 reports tax implicit equivalence scales for Belgium, and the bottom panel reports scales for Sweden. The tax implicit scales reported in the two panels of Figure 2 reflect the average scales taken over all 12 EU15 countries reported in Figure 1, in that they both display substantive variation with pre-tax income below 6000 Euros per month, before levelling out at higher incomes. Besides markedly different values at low income levels, a key difference between the tax implicit scales evaluated for the two countries is the degree to which family size is observed to influence tax treatment at higher incomes.

In the case of Belgium - in common with Austria, Germany and Luxembourg - tax implicit equivalence scales describe substantive differences between family units throughout the considered income range. In contrast, the tax implicit scales evaluated for Sweden display no variation by the number of adults in a family at pre-tax income above 3000 

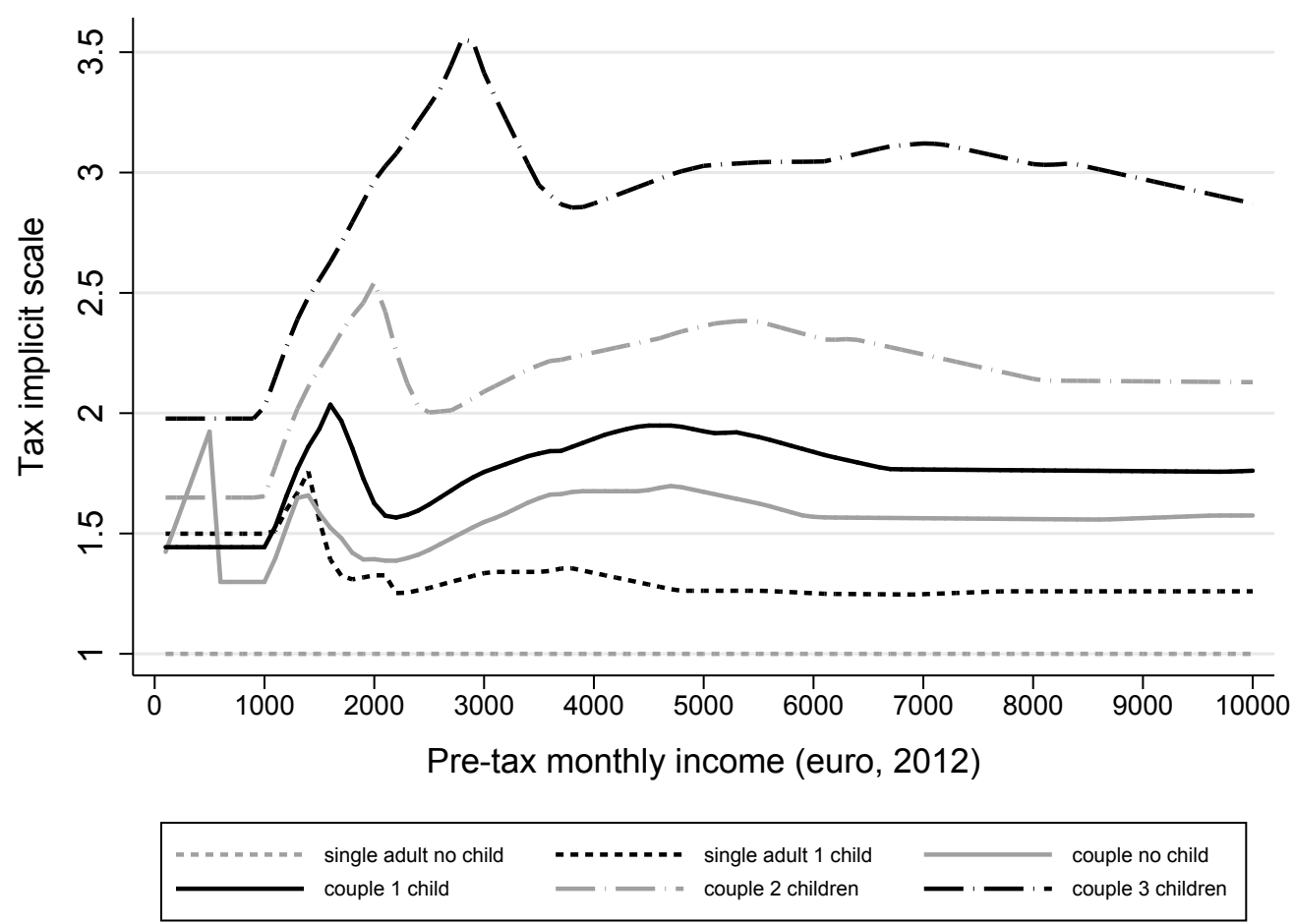

Panel A: Belgium

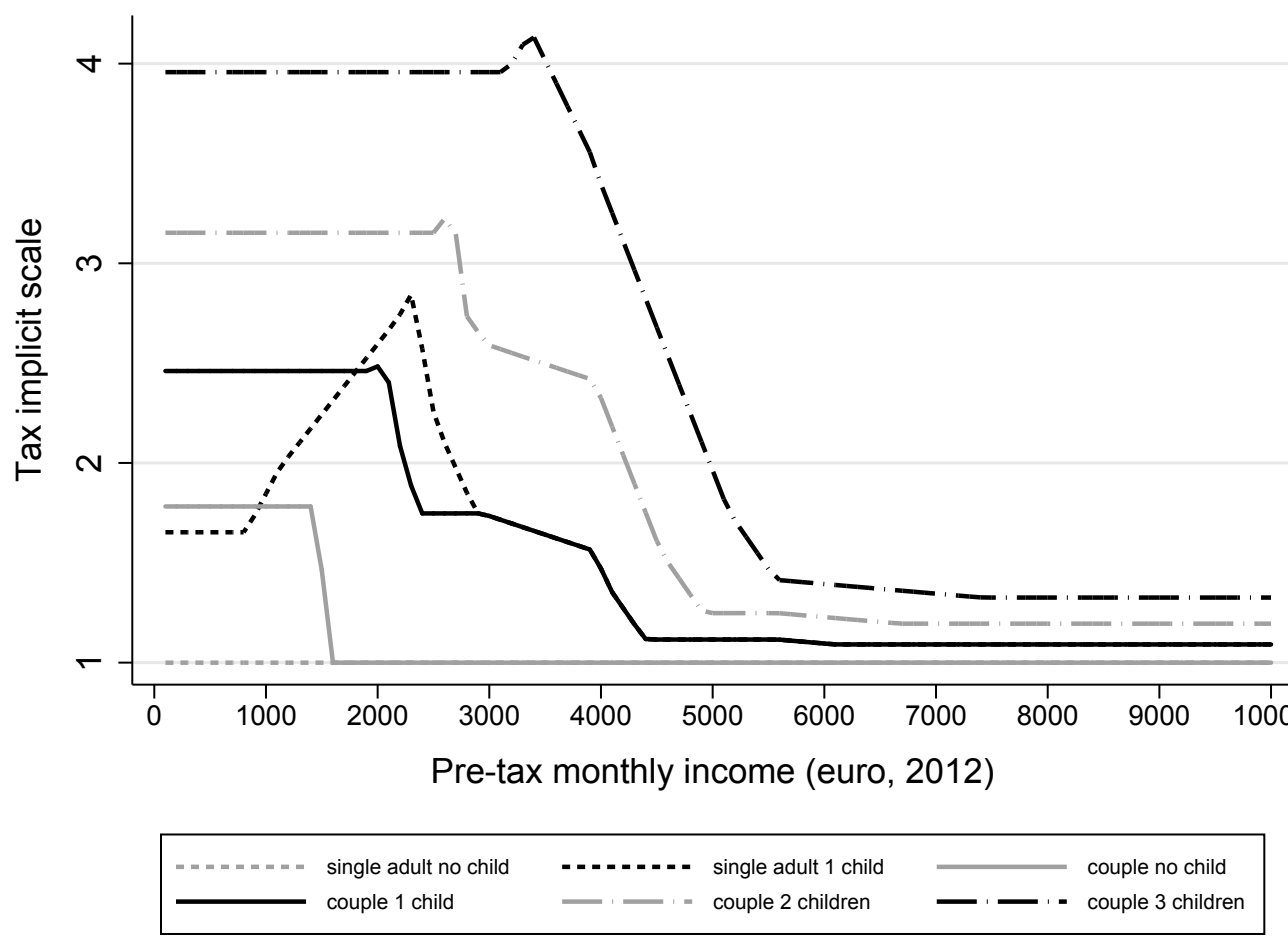

Panel B: Sweden

Source: Authors' calculations using data derived from Euromod v 1.10.2

Figure 2: Tax implicit equivalence scales by family type and pre-tax income for Belgium and Sweden in 2012 
Euros per month, and little variation by the number of dependent children above 5500 Euros per month. Similar observations apply to the tax implicit scales evaluated for Finland and the UK; the scales evaluated for Denmark, Ireland, the Netherlands and Portugal fall between these two extremes.

The muted emphasis that the Swedish transfer system places on family size and composition at high incomes (the average full-time wage in Sweden in 2012 was 3470 Euro per month) is consistent with a value judgement that the influence of consumption needs in determining a family's 'merit' for tax purposes declines as income rises. It seems to us reasonable to suppose, for example, that the decision to have children by high income households ought to be recognised as a reflection of personal preferences over which parents bear full financial responsibility. It is also notable that consumption (in the cross-section) tends to account for a smaller share of family budgets as income rises.

In contrast, relative to the tax implicit scales evaluated for Sweden, those for Belgium indicate that substantive provisions for family size are maintained by the tax and transfer system into the upper end of the income distribution. This would be consistent with the view that family size has an important bearing on consumption needs regardless of a family's income. It could also reflect provision of substantial tax incentives for fertility to high income individuals. The pattern conjectured by Becker and Tomes [30], for example, consists of a negative income effect on fertility in low-income groups and a positive income effect in higher-income groups. Recent studies by Milligan [31] and Cohen et al. [32] report empirical evidence that the effect of financial incentives on fertility is positive at high-income levels, but small and negative at low-income levels.

The tax implicit scales reported here reflect the features of the tax and transfer schemes applied in each country, and the ways in which those schemes interact both with each other and with pre-tax income. A summary of the broad characteristics of the tax and transfer systems in the sample of countries considered here is provided as part of the "Online Supplemental Material" to this paper. Our evaluation of this information suggests that two important features can be singled out as driving the tax implicit scales reported above. First, family (especially child) benefits are crucially important, as their level has a substantive bearing on the value of tax implicit scales at low income levels, while associated adjustments for pre-tax income (e.g. means testing) affect the extent 
and pace of convergence between similar units with and without children. ${ }^{13}$ Secondly, the structure of the tax system is important in determining the degree of convergence in scales, particularly at high incomes.

Three key alternative approaches to income taxation exist in our data: individual taxation (Austria, Denmark, Finland, the Netherlands, Spain, Sweden and the UK); family taxation without income splitting (Ireland); and family taxation with income splitting (Belgium, Germany, Luxembourg and Portugal). In context of a progressive rate structure, family taxation without income splitting will tend to treat couples less generously than individual taxation, to the extent that it prevents the lower earning spouse taking advantage of lower tax rates. In the analysis reported above, however, the assumption of a single income earner implies no effective difference between individual taxation and family taxation, as there is no tax levied on the activity of the non-earning spouse. In both of these contexts, the approach to taxation will tend to support a convergence between the tax implicit scales of singles and couples. In contrast, family taxation with income splitting will tend to favour couples rather than singles, as it allows couples to take maximum advantage of any progressivity in income tax rates. Adjustments to tax thresholds according to family type (as in Belgium, Ireland and Spain) further contribute to disparities between associated tax implicit scales for singles and couples.

The bearing on tax implicit scales of the features of tax-transfer policy discussed above can be readily seen in the scales for Belgium and Sweden that are displayed in Figure 2. Starting with family benefits at low incomes, although the Belgium and Swedish systems deliver similar levels of support to single adults with and without a dependent child, the Swedish system provides qualitatively higher benefits to couples, and particularly those with at least one dependent child. This relationship between levels of support offered in each country is reflected by the respective tax implicit scales at low pre-tax incomes reported in Table 1 and Figure 2. In both countries, while some family benefits are not means tested, social assistance schemes that provide a floor to post-tax income, vary with family size and are withdrawn approximately Euro for Euro in respect of any pre-tax income received. This withdrawal of benefits across all family types is responsible for the flat profiles of the tax implicit scales reported over low income ranges in Figure 2. As discussed in the preceding paragraph, Belgium

\footnotetext{
${ }^{13}$ Family benefits were not taxable in 2012 in the 12 EU countries in our sample.
} 
and Sweden employ substantively different approaches to taxation; whereas Belgium levies taxes at the family level and permits income splitting between spouses, Sweden taxes at the individual level. Furthermore, the thresholds used to administer progressive marginal tax rates are designed to respond to family circumstances in Belgium, but are fixed in Sweden. These differences in approaches to taxation drive the convergence of tax implicit scales at high incomes reported for Sweden, and the dispersed scales at high incomes reported for Belgium.

\section{Discussion}

This paper describes a simple and tractable method for identifying equivalence scales that reflect the value judgements implicit in a tax and transfer system. Identification of the implicit relativities is (in general) obtained by assuming that the tax function mapping fiscal merit and net transfers satisfies two basic properties: the principle of horizontal equity, which requires that tax units of equal tax merit in context of a tax should also be of equal merit if all taxes were (ceteris paribus) withdrawn; and the principle of tax independence, which requires the fiscal merit of tax units to be independent of the tax function.

The paper reports results obtained from an illustrative application that compares tax implicit scales evaluated for 12 European countries in 2012. The tax implicit scales that are reported vary positively with tax unit size, and describe substantial variation with pre-tax income. The variation with income is in contrast to the common assumption of base independence in the consumer demand literature, but is consistent with results recently reported in the empirical literature.

Cross-country averages for the tax implicit scales generate a surprising set of stylised results: at low incomes, each additional household member increases the tax implicit scale by approximately 0.5 , relative to 1.0 for the first adult; at high incomes, the average tax implicit scales describe variation that is remarkably similar to the modified OECD scale. Beyond these high-level stylisations, the reported tax implicit scales reveal important differences between countries. For example, whereas tax implicit scales at high incomes increase substantively with the number of tax unit members in Austria, Belgium, Germany and Luxembourg, they show little variation in Sweden, Finland and the UK.

Two qualifications are associated with the tax implicit scales reported in the paper. 
First, they are evaluated on tax-transfer systems described for a single year, and given the dynamic nature of modern transfer systems - consequently do not provide any indication of the extent to which the identified relativities persist through time. It is suggested that the cross-country averages - by aggregating over diverse political and administrative contexts - may provide a better indication of persistent value judgements implicit in (EU) transfer policy. Secondly, the equivalence scales that are reported were evaluated using Euromod version 1.10.2, and consequently only account for policy as it is represented in the model. A potentially important omission from the analysis is the impact of in-kind benefits, as these are not projected by Euromod. Analysis of these issues remains for further research.

A desirable property of tax implicit equivalence scales is that they provide an explicit description of the value judgements (implicitly) made by the government when acting in its role as administrative agent for society. These value judgements are interesting in their own right, and in many countries are highly opaque. Furthermore, it seems reasonable to suppose that the complexity and fragmented nature of many modern transfer systems may have detached the relative tax treatment of heterogeneous individuals from popular perceptions concerning relative needs. In such contexts, cutting through the complexity to produce transparent measures of relative tax treatment may help to improve the evidence base for policy discussion, design and reform.

There is a lot more to tax design than reflecting underlying consumption needs; one common alternative objective is to incentivise socially desirable behaviour. Comparison of tax implicit scales with equivalence scale estimates based on consumer demand theory can provide a useful indication of tax incentives over a broad range of characteristics. If, for example, the tax system makes a larger adjustment for young children than implied by equivalence scales estimated from consumption behaviour, then it is suggestive of a the transfer system structured to encourage increased fertility, or to meet a distributional objective of alleviating child poverty.

One common use of equivalence scales is as a control to aid comparisons of a financial metric (e.g. consumption, income) between heterogeneous demographic units (e.g. families, households). In this context, the traditional motivation for using equivalence scales is to adjust the financial metric to a comparable welfare basis. Interpretation of a financial metric equivalised using a tax implicit scale is consequently complicated by the existence of non-welfarist considerations in the design and implementation of tax and transfer policy. 
The analytical framework described in this paper indicates that tax implicit scales can be used to equivalise a financial metric observed among heterogeneous tax units to a comparable basis in terms of 'tax merit'. Tax merit is a new concept, and further analysis is required to appreciate its implications in context of the existing distributional literature. Key issues for consideration include the extent of intertemporal persistence of value judgements implied by tax implicit scales (and hence of relative tax merit), the sources of variation both within and between countries, and a better appreciation of the role of alternative motives underlying tax and transfer policy. Each of these inter-related subjects is of stand-alone interest, and we believe their role in providing support for the use of tax implicit scales for distributional analyses would be valuable for (at least) two reasons.

Firstly, although tax implicit scales may depend on factors that extend beyond simple welfare comparisons, it is reasonable to expect that a consideration of inter-unit welfare will lie at the heart of any well-designed tax-transfer system. Such scales, if properly understood, could consequently off-set the conceptual problems associated with traditional (demand) analysis. Secondly, the absence of a generally accepted correct approach for empirically identifying an equivalence scale that is appropriate for making welfare comparisons focusses attention on associated sensitivity analysis. In this regard, the tax implicit equivalence scales that we suggest here have the advantages that they can be objectively observed, and are based on a qualitatively different set of considerations to existing alternatives. These considerations underly our view that, if properly understood, tax implicit scales would present a valuable alternative for distributional analyses to the 'subjective' and 'indifference' scales that have been suggested in the contemporary literature.

Furthermore, there are at least some contexts in which equivalising on the basis of tax implicit scales can help to improve the internal consistency of distributional analyses, even if the concept of 'tax merit' is not illuminated beyond the current study. For example, where an analysis of inequality does not adjust post-tax incomes by the relevant tax implicit scales, then at least part of the measured inequality will be attributable to differences in the value judgements concerning relative needs assumed by the analyst, and those (implicitly) made by the respective tax authorities (e.g. van de Ven and Creedy [33]). This is most evident in distributional analyses of re-ranking, which explore how the redistributive effect of a tax system is affected by changes in the rank-order of 
individuals from the pre- to the post-tax income distributions. ${ }^{14}$ Such studies commonly adjust incomes by an exogenously assumed equivalence scale, leading to the critique that this "amounts to "imposing [horizontal inequity] from outside" if the tax is not, in fact, a family income tax designed to be coherent with an equivalence scale - or indeed if it is and the scale selected by the analyst is not the same as the one being used by the policy maker" (Lambert [38], p. 76). Use of tax implicit equivalence scales can help to allay such concerns.

\section{References}

[1] Deaton, A. and Muellbauer, J.: Economics and Consumer Behavior. Cambridge University Press, Cambridge, (1980).

[2] Coulter, F. A. E., Cowell, F. A., and Jenkins, S. P.: Bulletin of Economic Research 44, 77-124 (1992).

[3] Chiappori, P.: Economic Journal 126, 523-545 (2016).

[4] Blundell, R. and Lewbel, A.: Journal of Econometrics 50, 49-68 (1991).

[5] Pollak, R. A. and Wales, T. J.: American Economic Review 69, 216-221 (1979).

[6] Muellbauer, J.: Journal of Economic Theory 10, 269-283 (1975).

[7] Hagenaars, A., de Vos, K., and Zaidi, A.: Poverty Statistics in the Late 1980s: Research based on micro-data. Eurostat, Luxembourg, (1994).

[8] Orshansky, M.: Social Security Bulletin 28, 3-29 (1965).

[9] Browning, M., Chiappori, P.-A., and Lewbel, A.: Review of Economic Studies 80, 1267-1303 (2013).

[10] Bishop, J., Grodner, A., Liu, H., and Ahamdanech-Zarco, I.: Journal of Economic Inequality 12, 265-278 (2014).

[11] Olken, B. A.: Journal of Public Economics 89, 545-566 (2005).

[12] Lall, S. V., van den Brink, R., Dasgupta, B., and Leresche, K. M.: World Bank Policy Research Working Paper 6173, (2012).

\footnotetext{
${ }^{14}$ See, for example, [34], [35], [36], [37].
} 
[13] HMSO.: Report No. 6, Lower Incomes, Cmnd 7175, (1978).

[14] Stewart, M. B.: Review of Income and Wealth 55, 907-929 (2009).

[15] Hirsch, D.: A Minimum Income Standard for the UK in 2013. Joseph Rowntree Foundation, York, (2013).

[16] Storms, B. T., Goedem, T., van den Bosch, K., and Devuyst, K.: ImPRovE Methodological Paper 13/02, (2013).

[17] Atkinson, A. B. and Stiglitz, J. E.: Lectures on Public Economics. McGraw-Hill, Singapore, (1980).

[18] Plotnick, R.: Journal of Public Economics 17, 373-391 (1982).

[19] Lewbel, A.: Journal of Public Economics 39, 377-391 (1989).

[20] Blackorby, C. and Donaldson, D.: Social Choice and Welfare 10, 335-361 (1993).

[21] Donaldson, D. and Pendakur, K.: Journal of Public Economics 88, 175-208 (2003).

[22] Seneca, J. J. and Taussig, M. K.: Review of Economics and Statistics 53, 253-262 (1971).

[23] Pashardes, P.: Journal of Public Economics 58, 143-158 (1995).

[24] Blundell, R., Duncan, A., and Pendakur, K.: Journal of Applied Econometrics 13, 435-461 (1998).

[25] Pendakur, K.: Journal of Econometrics 88, 1-40 (1999).

[26] Dickens, R., Fry, V., and Pashardes, P.: Economic Journal 103, 359-368 (1993).

[27] Sutherland, H. and Figari, F.: EUROMOD Working Paper No. 8/13, (2013).

[28] Ahola, E., Honkanen, P., Tervola, J., and Valaste, M.: EUROMOD Country Report, (2014).

[29] Paulus, A., Sutherland, H., and Tsakloglou, P.: Journal of Policy Analysis and Management 29, 243-266 (2010).

[30] Becker, G. and Tomes, N.: Journal of Political Economy 84, S143-S162 (1976). 
[31] Milligan, K.: Review of Economics and Statistics 87, 539-555 (2005).

[32] Cohen, A., Dehejia, R., and Romanov, D.: Review of Economics and Statistics 95, $1-20(2013)$.

[33] van de Ven, J. and Creedy, J.: Bulletin of Economic Research 57, 13-36 (2005).

[34] Ebert, U. and Lambert, P. J.: Public Finance Review 32, 426-440 (2004).

[35] van de Ven, J., Creedy, J., and Lambert, P.: Oxford Bulletin of Economics and Statistics 63, 381-394 (2001).

[36] Aronson, J. R., Johnson, P., and Lambert, P. J.: The Economic Journal 104, 262-270 (1994).

[37] Jenkins, S. P.: Scottish Journal of Political Economy 24, 65-76 (1988).

[38] Lambert, P. J.: In Household Behaviour, Equivalence Scales, Welfare and Poverty, Dagum, C. and Ferrari, G., editors. Physica-Verlag, New York (2004). 